\title{
Childhood prevention of coronary heart disease
}

\author{
June K. Lloyd ${ }^{1 *}$ and Richard J. West ${ }^{2}$ \\ ${ }^{1}$ Professor and ${ }^{2}$ Senior Lecturer, St George's Hospital Medical School, University of London, London, UK.
}

The concept that doctors who care for children have a role to play in the prevention of atherosclerosis and coronary heart disease is not new. Almost 20 years ago Otto Wolff, in a lecture to the Canadian and New England Pediatric Societies, laid the responsibility on paediatricians to 'detect these familial conditions (hyperlipidaemias) in childhood, when the arterial tree is still relatively unaffected, and to attempt to lower the serum lipid levels in the hope that, thereby, the development of atheroma and coronary disease will be delayed' (Wolff, 1967). Since this time there have been innumerable papers on the same theme from many countries throughout the world. All have concentrated on the need to identify and modify risk factors in childhood, and the five point plan advocated by Kannel \& Dawber (1972) involving the prevention of obesity, the detection and prevention of hyperlipidaemia and hypertension, the discouragement of cigarette smoking and the encouragement of physical activity has been recently restated by Voller \& Strong (1981). These American authors advocate that some preventive measures, those involving general dietary modification, anti-cigarette smoking propaganda and the encouragement of physical activity should be adopted as public policy for all children, but that the task of identifying those children at highest risk must lie with the primary physician, presumably the paediatrician in the USA, and the general practitioner in the UK.

Why have these admirable objectives been so slow to get off the ground, at least in the UK? Is it just that prevention has remained a rather unfashionable subject in Medicine, or is it at least in part due to scepticism about the validity of the assumption that the risk factors defined in epidemiological studies of adults are equally applicable in children? Furthermore, is there evidence that control of risk factors in children is practicable in either the short or long term and will actually delay the development of the atherosclerotic process? The answers to these questions are by no means clear and in this review we shall attempt to summarize some of the evidence and reach some conclusions.

* Correspondence and present address: Professor J.K. Lloyd, M.D., F.R.C.P., Institute of Child Health, 30 Guilford Street, London WC1N 1EH, UK.

\section{Will risk factors identified in childhood persist into adult life?}

An unequivocally positive answer can be given for cigarette smoking. There is abundant evidence that children who smoke regularly are highly likely to continue to be smoking adults, and every opportunity should be taken to try to prevent children acquiring the smoking habit. No answer can be provided for physical activity (or inactivity). We just do not know whether slothful children become sedentary adults or whether active athletic children will retain this way of life.

In respect of obesity, this subject is considered in detail elsewhere in this volume (Stark \& Lloyd, 1986), and its role as an independent risk factor for coronary heart disease is no longer so certain; however, the studies of Otto Wolff and his colleagues have clearly established that the majority of obese children are not obese in early adult life, although the risk rises for obesity in adolescence (Stark et al., 1981).

Studies of the degree to which blood pressure levels or plasma lipid concentrations will stay in the same centile rank (tracking) have been carried out over periods of 5-8 years (Clarke et al., 1978). For blood pressure it seems unlikely that single observations of systolic blood pressure in children will accurately predict adult hypertension, but for adolescents with borderline hypertension who have a strong family history of essential hypertension, who are obese, have a high resting heart rate and who have an increased cardiovascular response to mental stress the risk of progression to sustained essential hypertension is much higher (Falkner et al., 1981).

Tracking of plasma cholesterol and of low and high density lipoprotein cholesterol in children aged 7-14 years over 5 year periods shows rànk correlations of around 0.6 (Laskarzewski et al., 1979). Children with values in the upper centiles are more likely to maintain this position if their parents are also in the higher centiles. A more recent study (Orchard et al., 1983) of 12 year old boys followed up for 9 years showed that only $49 \%$ of those in the top quintile for plasma cholesterol at baseline were similarly placed at follow-up. Interestingly, the children who dropped out of the top quintile tended to be less obese, smoked less frequently and tended to be more active than those in 
the top quintile as adults. This emphasizes again the inter-relationship between various risk factors.

The status of raised plasma lipids as risk factors in childhood is, however, quite different in the monogenically inherited disorders of lipoprotein metabolism. Familial hypercholesterolaemia, the dominantly inherited disorder caused by a defect (or defects) of the receptor mechanism for uptake of low-density lipoprotein (LDL) into cells, and characterized by high circulating plasma cholesterol and LDL carries a higher risk of early coronary heart disease than polygenic hypercholesterolaemia (Slack, 1974). The gene defect is fully expressed in childhood and therefore the raised cholesterol in a child which is due to this disorder can truly be regarded as a risk factor. For the other inherited hyperlipidaemias the position is less clear. Familial hyperchylomicronaemia does not appear to predispose to early atherosclerosis but for the remaining hypertriglyceridaemias full expression of the biochemical abnormality may not occur during childhood.

\section{Will risk factor control delay the development of atherosclerosis?}

To improve risk factor control in childhood with the objective of delaying the development of atherosclerosis and thus of coronary heart disease remains largely an act of faith. The hard evidence that control of risk factors is effective is entirely in adults and so far has been confined to studies in middle aged men. Diet and drug trials in populations of such men have indeed resulted in both a reduction in mean plasma cholesterol concentrations and also in coronary events (Oliver, 1984).

The most recent study from the USA selected men who had hypercholesterolaemia, treated them with cholestyramine, and, over a 9 year period showed a significant reduction in both plasma cholesterol and LDL levels and in various indices of coronary heart disease (Lipid Research Clinic Program, 1984). This study has been widely accepted as sufficient basis for recommending a vigorous approach to lowering cholesterol concentrations in the general population (Consensus Conference, 1985) although not all would agree (Oliver, 1985; Ahrens, 1985).

For children no studies exist, and even for children at highest and identifiable risk, namely those with familial hypercholesterolaemia, the task of maintaining follow-up for $30-40$ years is formidable and probably impracticable. However, the development of non-invasive means of visualizing arteries, and the coronary vessels in particular, may enable us to follow the progression, or even regression, of lesions over a much shorter time span. Until such time the 'act of faith' approach can be supplemented by some anec- dotal evidence. For 15 years we have been following a boy with the severe homozygous form of familial hypercholesterolaemia, whose 3 other similarly affected siblings had all died before the age of 11 years. Since the age of 1 year his plasma cholesterol has been lowered from pre-treatment values of around $25 \mathrm{mmol} / \mathrm{l}$ to values of around $16 \mathrm{mmol} / 1$. Even though his levels have clearly remained much too high he has as yet no xanthomata or evidence of significant coronary or aortic root disease (as judged by angiography) (West et al., 1985). This experience encourages us to believe that lowering plasma cholesterol is worthwhile as a preventive measure in children with familial hypercholesterolaemia, even if normal levels cannot be achieved.

\section{Can risk factors be controlled in children?}

Our main interest centres on control of plasma cholesterol. In the general childhood population it can be assumed that there is likely to be a modest fall in mean values of cholesterol if there is a reduction in total dietary fat (with an increase in the proportion of polyunsaturated fat) as recommended by the COMA Report for all over the age of 5 years (Committee on Medical Aspects of Food Policy, 1984). National eating habits are constantly changing and affeop children as well as adults. It is believed that eating habits started in childhood will tend to persist and although there is no evidence for this, nutritio education at school and a change in the type of school meals provided may help to promote sensible dietary habits.

For children with familial hypercholesterolaemia more stringent dietary measures can reduce plasma cholesterol by about 10 per cent but in only a minority will diet alone provide adequate control of plasma cholesterol in the long term (West et al., 1975). Most children will require drug treatment and at present an ion exchange resin such as cholestyramine is the drug of choice. Compliance with drug therapy, although better than for diet, is, however, disappointing in that slightly less than half the children can be expected to be controlled by the end of 8 years (West et al., 1980). Other drugs such as nicotinic acid and clofibrate may have long term side effects; bezafibrate although reasonably effective in short term studies (Wheeler $e t$ al., 1985) has not been subjected to long term evaluation in children.

\section{Should screening for risk factors be carried out in childhood?}

In our opinion there is at present no justification for population screening of plasma cholesterol or other 
lipids in children. Height, weight and possibly blood pressure should certainly be measured in all children at all 'routine' medical examinations but not with the objective of labelling children as 'at risk' for atherosclerosis.

Selective screening for familial hypercholesterolaemia is, however, probably justified in children over 1 year of age. The diagnosis is not always straightforward; there is no absolute cut-off point for either total plasma cholesterol or LDL cholesterol at which the diagnosis can be made and more precise diagnostic procedures such as routine measurement of lipoprotein receptors or identification of the gene defect are still for the future. If there is a first degree family relative with the disorder then Leonard et al. (1977) showed that the cholesterol value at which minimal classification will occur was $6.7 \mathrm{mmol} / 1$. Screening should thus be confined to the families of a known hypercholesterolaemic individual, and may perhaps be extended to families in which early coronary heart disease has occurred, even though it is not certain that familial hypercholesterolaemia is the cause of the ischaemic heart disease. Before the diagnosis is finally made a second estimation of plasma lipids should always be carried out (some authors recommend three estimations in children of early coronary subjects) (Andersen $e t$ al., 1981) and HDL-cholesterol also estimated to find out if the high cholesterol value is indeed the result of raised LDL concentrations. Diagnosis during the first year of life, though possible, presents more difficulty because of the lability of plasma lipids during the milk feeding period, and we feel in any case that a change in the pattern of infant feeding is not indicated.

Once the diagnosis of familial hypercholesterolaemia has been established in a child and treatment started, it is essential that careful follow-up is maintained. Management by, or at least in conjunction with, a clinic specializing in childhood lipid disorders is highly desirable. For these children special attention should of course be paid to the other risk factors such as blood pressure, obesity, and cigarette smoking. Concern has been expressed that detection and treatment of hypercholesterolaemia in symptomfree children may cause psychological harm. For many of the families there is already emotional distress because a coronary attack has occurred in a parent or other near relative. In our experience such families are usually relieved to have tests done and it is clearly beneficial if they can be told that a child has not inherited familial hypercholesterolaemia. For those children who are affected some stress is undoubtedly created; we know of no studies of the magnitude of this. For each family individual decisions will have to be made.

\section{Conclusions}

1. The prevention of atherosclerosis should be of concern to all doctors looking after children.

2. Every effort should be made to prevent children acquiring the habit of cigarette smoking.

3. The overall modest reduction in dietary fat (with relative increase in the proportion of polyunsaturated fat) introduced for the population as a whole (with the exception of infants and children under 5 years) (Committee on Medical Aspects of Food Policy, 1984) may lead to a modest fall in mean plasma cholesterol concentrations.

4. At present there is no case for screening all children for hypercholesterolaemia.

5. Selective screening of children in families known to have familial hypercholesterolaemia, in whom the risk of coronary heart disease is especially high, and possibly also in those with a history of early coronary heart disease, should be undertaken. The diagnosis and treatment of affected children should be carried out in conjunction with departments with experience in the management of such children.

\section{References}

ANDERSEN, G.E., HEJL, M., CHRISTENSEN, N.C., BOTT, H., LOUS, P. \& FRIIS-HANSEN B. (1981). Hyperlipidaemia among 1,407 Danish children whose fathers have died from ischaemic heart disease before age 45 . Acta Paediatrica Scandinavica, 70, 843.

AHRENS, E.H. $\mathrm{J}_{\mathrm{R}}$ (1985). The diet heart question in 1985: has it really been settled. Lancet, i, 1085.

CLARKE, W.R., SCHROTT, H.G., LEAVERTON, P.E., CONNOR, W.E. \& LAUER, R.M. (1978). Tracking of blood lipids and blood pressures in school children. Circulation, 58, 626.

COMMITTEE ON MEDICAL ASPECTS OF FOOD POLICY

(1984). Diet in Relation to Cardiovascular Disease. Department of Health and Social Security. H.M. Stationery Office: London.

CONSENSUS CONFERENCE (1985). Lowering blood cholesterol to prevent heart disease. Journal of the American Medical Association, 253, 2080.

FALKNER, B., KUSHNER, H., ONESTI, G. \& ANGELAKOS, E.T. (1981). Cardiovascular characteristics in adolescents who develop essential hypertension. Hypertension, 3, 521 .

KANNEL, W.B. \& DAWBER, T.R. ((1972). Atherosclerosis as a pediatric problem. Journal of Pediatrics, 80, 544.

LASKARZEWSKI, P., MORRISON, J.S., DE GROOT, I., KELLY, 
K.A., MELLIES, M.J., KHOURY, P. \& GLUECK, C.J. (1979). Lipid and lipoprotein tracking in 108 children over a 4 year period. Pediatrics, 64, 584.

LEONARD, J.V., WHITELAW, A.G.L., WOLFF, O.H., LLOYD, J.K. \& SLACK, J. (1977). Diagnosing familial hypercholesterolaemia in childhood by measuring serum cholesterol. British Medical Journal, 1, 1566.

LIPID RESEARCH CLINIC PROGRAM (1984). The relationship of reduction in incidence of coronary heart disease to cholesterol lowering. Journal of the American Medical Association, 251, 367.

OLIVER, M.F. (1984). Hypercholesterolaemia and coronary heart disease: an answer. British Medical Journal, 288, 423.

OLIVER, M.F. (1985). Consensus or nonsensus: Conference on coronary heart disease. Lancet, i, 1087.

ORCHARD, T.J., DONAHUE, R.P., KULLER, L.H., HODGE, P.N. \& DRASH, A.L. (1983). Cholesterol screening in childhood: does it predict adult hypercholesterolaemia. Journal of Pediatrics, 103, 687.

SLACK, J. (1974). Genetic differences in liability to atherosclerotic heart disease. Journal of the Royal College of Physicians, London, 8, 115.

STARK, O., ATKINS, E., WOLFF, O.H. \& DOUGLAS, J.B.
(1981). Longitudinal study of obesity in the National Survey of Health and Development. British Medical Journal, 2, 13.

STARK, O. \& LLOYD, J.K. (1986). Some aspects of obesity in childhood. Postgraduate Medical Journal, 62, 87.

STRONG, J.P. \& MCGILL, H.C. (1969). The pediatric aspects of atherosclerosis. Journal of Atherosclerosis Research, 9, 251.

VOLLER, R.D. \& STRONG, W.B. (1981). Paediatric aspects of atherosclerosis. American Heart Journal, 101, 815.

WEST, R.J., FOSBROOKE, A.S. \& LLOYD, J.K. (1975). Treatment of children with familial hypercholesterolaemia. Postgraduate Medical Journal, 51 (Suppl. 8), 82.

WEST, R.J., GIBSON, P.J. \& LLOYD, J.K. (1985). Treatment of homozygous familial hypercholesterolaemia: an informative sibship. British Medical Journal, 2, 1079.

WEST, R.J., LLOYD, J.K. \& LEONARD, J.V. (1980). Long-term follow-up of children with familial hypercholesterolaemia treated with cholestyramine. Lancet, ii, 873.

WHEELER, K., WEST, R.J., LLOYD, J.K. \& BARLEY, J. (1985). Double blind trial of bezafibrate in familial hypercholesterolaemia. Archives of Disease in Childhood, 60, 34.

WOLFF, O.H. (1967). Primary disorders of the serum lipoproteins in childhood. Pediatrics, $\mathbf{4 0 , 1 .}$ 